\title{
PITUAH PAIKEK: PENCIPTAAN KARYA TARI BERANGKAT DARI RITUS PERALIHAN MALAM BAINAI DI SUMATERA BARAT
}

\author{
Cici Wulandari ${ }^{*}$, Susas Rita Loravianti ${ }^{2 *}$, Novesar Jamarun ${ }^{3 *}$ \\ Penciptaan Seni Tari Program Pascasarjana \\ Institut Seni Indonesia Padangpanjang \\ Jl. Bahder Johan, Guguak Malintang, Padangpanjang, Kota Padangpanjang, Kode Pos 27126 \\ Sumatera Barat. Indonesia \\ Email: ci.moren19@gmail.com,loraviantisusasrita@gmail.com,novesar62@yahoo.com
}

\begin{abstract}
Abstrak
Karya Pituah Paikek adalah karya tari yang berangkat dari budaya Malam Bainai di Sumatera Barat. Ide penciptaan berfokus kepada makna filosofis dari inai di kuku calon pengantin wanita. Rumusan penciptaan dari karya Piuah Paikek ini adalah bagaimana menginterpretasikan makna dan simbol dari kuku bainai calon pengantin wanita menjadi sebuah karya tari. Tujuan dari karya tari ini adalah menampilkan pengalaman dari ritus peralihan Malam Bainai ke dalam bentuk tari kontemporer dengan tipe dramatik. Metode penciptaan yang digunakan, antara lain: riset, eksplorasi, improvisasi, pembentukan dan evaluasi. Penciptaan karya tari Pituah Paikek ini menghasilkan karya tari yang memiliki tiga bagian, yaitu: bagian pertama sebagai representasi simbolis dari aktivitas bainai, bagian kedua adalah representasi simbolis dari makna jari dan bagian ketiga adalah penegasan setiap nilai dari jari bainai.
\end{abstract}

Kata Kunci: pituah paikek, malam bainai, kontemporer.

\begin{abstract}
Pituah Paikek's work is a dance work that departs from the Malam Bainai culture in West Sumatra. The idea of creation focuses on the philosophical meaning of the henna on the bride's nails. The formulation of the creation of Piuah Paikek's work is how to interpret the meaning and symbols of the bride's bainai nails into a dance work. The purpose of this dance work is to present the experience of the Bainai Night rite of passage into a contemporary dance form with a dramatic type. The creation methods used include: research, exploration, improvisation, formation and evaluation. The creation of this Pituah Paikek dance work produces a dance work that has three parts, namely: the first part is a symbolic representation of the Bainai activity, the second part is a symbolic representation of the meaning of the finger and the third part is an affirmation of each value of the Bainai finger.
\end{abstract}

Keywords: pituah paikek, malam baianai, contemporary.

\section{PENDAHULUAN}

Proses pernikahan suku Minangkabau merupakan prosesi yang sangkral dan esensial. Diwarisi secara turun temurun dan telah menjadi bagian dari kekayaan budaya Indonesia. Di Sumatera Barat, upacara perkawinan secara adat dikenal dengan sebutan Baralek Gadang. Setiap tahapan ritual, mulai dari pranikah hingga pasca-nikah sarat akan makna pendidikan budi pekerti. Salah satu prosesi vital dari ritual pernikahan suku Minangkabau adalah prosesi Malam Bainai.

Malam Bainai adalah tradisi memberikan inai pada kuku pengantin wanita. Tradisi malam Bainai dilakukan pada malam sebelum pernikahan berlangsung. Malam Bainai menjadi momentum calon pengantin untuk melepaskan masa lajangnya. Oktora (2017: 2-3) menambahkan bahwa Malam Bainai dilakukan untuk menjaga anak daro (pengantin wanita) dari berbagai gangguan sebelum pernikahan dilangsungkan. Malam Bainai juga dimanfaatkan sebagai ajang silaturahmi dan diskusi tentang persiapan acara pernikahan.

Warna merah di kuku calon pengantin wanita yang dihasilkan dari daun inai (daun pacar merah) merupakan tanda bahwa yang memakainya telah memiliki suami. Untuk pemasangannya sendiri harus mengikuti aturan adat yang berlaku. Pemasangan inai harus dilakukan oleh kedua orang tua atau kerabat dari pengantin wanita (Sylvia, 2014: 72).

Wawancara dengan Zaimiati pada tanggal 23 Agustus 2019, Ia mengatakan bahwa malam Bainai memiliki rangkaian prosesi dan urutan yang harus disesuaikan dengan maknanya. Tahapan dari prosesi Malam Bainai 
antara lain: Tepian Mandi, Bamandi-mandi, Maniti Kain Kuniang, Bainai, Penutup. Seiring perkembangan zaman prosesi Malam Bainai mengalami perubahan yang signifikan, di mana pada masa dahulunya prosesi Malam Bainai hanya dilakukan secara sederhana saja, tetapi seiring perkembangan zaman Malam Bainai sudah dikemas dengan lebih menarik yang diiringi taritarian dan musik. Banyak di antara masyarakat yang tidak memahami dan tidak melaksanakan prosesi Malam Bainai dikarenakan keterbatasan waktu dan biaya sehingga pelaksanaan prosesi Malam Bainai hanya dilakukan dari kalangan menengah keatas. Wawancara Zaimiati, Padang 23 Agustus 2019.

Musra Dahrizal atau biasa dipanggil dengan Mak Katik Rajo Mangkuto menambahkan bahwa fungsi dasar pada inai yaitu sebagai pengusir setan karena pada dasarnya wanita banyak di pengaruhi oleh aura-aura negatif. Sebelum prosesi Malam Bainai wanita terlebih dahulu melakukan mandi taubat dan kemudian diikuti dengan sholat taubat. Calon pengantin wanita tidak boleh dalam keadaan menstruasi atau datang bulan begitupun dengan orang yang melekatkan inai pada calon pengantin wanita. Wawancara Mak Katik, Padang: 18 Februari 2021.

Pemasangan inai di setiap kuku jari calon pengantin wanita memiliki makna filosofis yang telah dijunjung tinggi oleh masyarakat Minangkabau. Inai di ibu jari melambangkan Bundo Kanduang sebagai penjaga atau perekat rumah tangga. Inai di jari telunjuk melambangkan "Tau Dinan Ampek", yaitu memahami tentang rasa, persiksa, malu dan sopan santun. Inai di jari tengah melambangkan penengah dan tiang peyanggah rumang tangga. Inai di jari manis melambangkan kekuatan batin, getaran dan daya tarik wanita. Inai di jari kelingking melambangkan wanita yang lemah lembut.

Karya Pituah Paikek mengangkat tentang ritus peralihan perempuan di Malam Bainai. Perspektif yang difokuskan adalah pesan moral dan nasihat untuk kaum perempuan, khususnya perempuan Minangkabau. Pituah memiliki arti petuah dan Paikek berasal dari kata pengikat. Sedangkan Pituah Paikek adalah nasihat yang baik dari orang tua untuk calon pengantin yang akan membina rumah tangga. Inai sebagai simbol dari Pituah Paikek menegaskan bahwa perempuan memiliki tanggung jawab yang besar ketika menjadi seorang istri sekaligus seorang ibu.

Karya tari ini mengusung konsep tari kontemporer dan mengusung tema sosial. Tipe tari yang dipilih adalah tipe dramatik, agar setiap pesan yang disampaikan lebih komunikatif. Gerak dasar yang dieksplorasi adalah gerak Randai Ulu Ambek. Sedangkan untuk komposisi musik disusun berdasarkan instrumen tradisional, seperti saluang, bansi dan dendang .

\section{KAJIAN TEORI}

\section{Teori Kreativitas}

Kreativitas tidak dihasilkan oleh adanya peniruan, penyesuaian, atau pencocokan terhadap pola-pola yang telah dibuat sebelumnya. Kreativitas menyangkut pemikiran imajinatif: merasakan, menghayati, menghayalkan dan menemukan kebenaran (Alma, 2003: 15-17).

\section{Teori Tari Kontemporer}

Tari kontemporer adalah manifestasi kreatif atas keberagaman suku dan pertanyaan kembali atas tradisi. Definisi tari kontemporer terpengaruh oleh pernyataan Peter Burger tentang seni avant-garde, yaitu seni yang memiliki kedudukan yang sejajar dan terbuka atas perbedaan (Supriyanto, 2018:7).

\section{Teori Semiotika}

Roland Barthes (dalam Kurniawan, 2001: 53). mengungkapkan bahwa semiotika adalah ilmu yang mempelajari tentang manusia yang memaknai sesuatu. Memaknai adalah upaya untuk mengungkap informasi yang terkandung di dalam objek dan mengkonstitusikannya menjadi sebuah sistem tanda.

\section{METODE PENELITIAN}

\section{Riset}

\section{1). Observasi}

Observasi dilakukan untuk mencari data yang dibutuhkan untuk mendukug konsep dan gagasan dalam pembentukan karya Pituah Paikek. Data yang diperoleh merupakan hasil dari pengamatan pengkarya terhadap budaya Malam Bainai. Pengamatan ini dilakukan di daerah Padang dan sekitarnya. Pada tahap ini pengkarya melakukan wawancara pada narasumber yang mengetahui dan pernah mengikuti prosesi Malam Bainai dan juga melakukan tinjauan pustaka guna mendapatkan informasi yang dibutuhkan.

Observasi selanjutnya dilakukan secara langsung, dengan cara menghadiri prosesi Malam Bainai, dan mendengarkan setiap petuah yang disampaikan Ninik Mamak, Bako dari pengantin wanita dan kerabat lainnya. Melakukan diskusi mengenai filosofi atau prosesi Malam Bainai, serta mengikuti prosesi Malam Bainai pada beberapa tempat sesuai dengan rangkaian prosesi dan perkembangan yang terjadi. Petuah dan nasehat-nasehat tersebut yang menjadi nilai dari setiap kuku jari yang dipasangkan inai. 
Gorga : Jurnal Seni Rupa

Volume 10 Nomor 02 Juli-Desember 2021

p-ISSN: 2301-5942 | e-ISSN: 2580-2380

\section{2). Wawancara}

Wawancara adalah sebuah percakapan dengan maksud tertentu. Percakapan itu dilakukan oleh dua pihak yaitu pewawancara dan yang diwawancarai memberikan jawaban atas pertanyaan dari pewawancara. Kegiatan ini juga terjadi antara satu individu dengan individu lainnya atau satu individu dengan suatu kelompok (Hadi, 2007: 145). Wawancara juga juga dilakukan untuk mencatat opini, perasaan, emosi dan hal lainnya yang berkaitan konsep yang digarap. Melalui wawancara pengkarya dapat memperoleh data yang lebih banyak sehingga pengkarya dapat mendapatkan informasi yang akurat dari informan. Informan yang diwawancarai yaitu teman pengkarya yang sudah menikah dan melalui prosesi Malam Bainai, Pemuka Adat, Masyarakat, Bundo Kandung Dan Budayawan.

Wawancara dengan narasumber utama yaitu Devi, sebagai perempuan Minangkabau yang baru saja melewati prosesi Malam Bainai. Dari narasumber utama ini, data yang didapatkan adalah hal apa yang dirasakan oleh seorang perempuan pada saat melakukan prosesi Malam Bainai. Devi mengatakan bahwa sebelum perempuan menjadi seorang istri, harus selalu menjaga tata krama dalam bersikap, sesuai aturan adat perempuan Minangkabau dalam menuju hari pernikahan. Setiap langkah atau hal yang dilakukan mempunyai batasan, kemudian perasaan yang di alami rasa bahagia bercampur kecemasan. Wawancara Cintya Devi, padang 23 Agustus 2019.

\section{Proses Kreatif}

\section{1). Eksplorasi}

Eksplorasi disebut juga penjelajahan atau pencarian, adalah tindakan mencari atau melakukan perjalanan dengan tujuan menemukan. Eksplorasi dirangsang dari isyarat-isyarat eksternal. Eksplorasi termasuk memikirkan, mengimajinasikan, merenungkan, merasakan dan juga merespon objek-objek atau fenomena alam yang ada (Hadi, 2012: 70).

Eksplorasi diawali oleh proses memikirkan, merenungkan, mengimajinasikan dan merasakan peristiwa pada proses ritual Malam Bainai yang akan dijadikan fokus persoalan untuk menemukan ide-ide baru berwujud sebuah konsep dalam garapan karya. Pada praktik penciptaan tari eksplorasi dipahami sebagai tindakan penjelajahan dengan rangsangan dan target tertentu (Yudiaryani, 2017: 96). Eksplorasi yang dilakukan dalam garapan karya Pituah Paikek melalui penjelajahan dengan rangsangan melalui eksplorasi gerak dengan sumber gerak tradisi pada salah satu tari tradisi silat uluambek. Pada karya Pituah Paikek ini eksplorasi dilakukan dengan cara melakukan gerakan sesuai dengan alur tanpa memikirkan keindahan terlebih dahulu, dan mengulang gerak-gerak tersebut untuk dapat diperhalus menjadi gerakan yang utuh.

Tahap selanjutnya memberikan materi pada penari dan memikirkan kenyamanan dan kualitas penari dalam bergerak sehingga penari tidak merasa terbebani dengan garakan tersebut. Penggambaran dilakukan untuk memancing daya inspirasi dan mencoba menggambarkan peristiwa Malam Bainai untuk selalu diingat dalam pemikiran masing-masing penari, sehingga penari dapat membayangkan dan mengungkapkannya melalui gerakan-gerakan yang dihasilkan dari tubuh penari. Selanjutnya adalah memindahkan ide gagasan kepada penari dan memberikan kebebasan kepada penari dalam melakukan eksplorasi gerak tetapi tetap dalam pengawasan koreografer. Tahap selanjutnya adalah mencoba menyatukan rasa dari penari satu dan penari lainnya.

\section{2). Improvisasi}

Improvisasi merupakan persiapan mental fisikal dan emosional yang mendukung perkembangan koreografi. Improvisasi merupakan cara menanamkan analisis, materi teoritis kedalam Soma-Psyche (ketubuhan dan jiwa). Improvisasi lebih bebas daripada eksplorasi. Improvisasi dapat distimulasi melalui respon indera, dalam pendekatan ini tubuh dibiarkan bergerak bebas dan spontan sebagai respon atas stimulus melalui indera (Yudiaryani, 2017: 97). Sebuah artikulasi daya gerak dan daya rasa, dimanfaatkan sebagai cara improvisasi guna melahirkan dinamika bagi terciptanya sebuah gagasan beserta segala kemungkinankemungkinan barunya. Improvisasi adalah cerminan dari rasa sensitivitas seorang manusia untuk mampu mendayagunakan dengan baik 'aksi dan reaksi' dalam tubuhnya sendiri.

Improvisasi akan berkembang dengan baik bila faktor kualitas kemampuan manusianya sudah mencukupi. Dibutuhkan sebuah kerangka yang kokoh dan terkonsep dengan baik agar improvisasi bisa bergerak lincah leluasa yang akhirnya dapat menemukan dan mengisi ruang-ruang yang tersedia terhadap karya tari. Pada tahap ini koreografer melakukan percobaanpercobaan gerak dengan penari untuk mendapatkan gerak baru dan dipadukan dengan unsur, ruang, waktu dan tenaga. Karya Pituah Paikek ini memakai improvisasi yang tergarap, maksudnya menyusun beberapa materi yang diberikan pada penari untuk dapat dikembangkan pada adegan-adegan tertentu. Tidak hanya memberi kepercayaan pada penari untuk melakukan gerak-gerak spontan. 


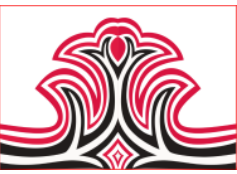

3). Pembentukan

Pembentukan dalam karya tari adalah proses pemilihan materi dan penyusunan serta merangkai keseluruhan menjadi sebuah karya tari. Pada tahap ini hasil-hasil yang telah didapatkan pada tahap ekplorasi dan improvisasi dipadu dengan musik untuk menjadikan kesatuan karya yang utuh. Penata mencoba merangkai gerak melalui eksplorasi dan improvisasi sehingga melahirkan bentuk baru, namun tidak semua gerak yang dapat dipakai, tapi ada kemungkinan penata harus membuat gerak baru lagi karena dalam proses pembentukkan karya akan ada perubahan dan penata harus lebih cepat dan kreatif dalam memikiran gerak baru jika ada penambahan gerak.

Karya Pituah Paikek disusun melalui pembentukkan dengan cara menggabungkan tahap eksplorasi dan improvisasi dengan membuat gerak baru untuk penggabungan sehingga melahirkan kemungkinan gerak baru. Bentuk-bentuk gerak yang diberikan pengkarya mulai menyatukan bentuk-bentuk menjadi kalimat dalam gerak yang memberikan makna dan simbol terhadap konsep karya. Karya tari Pituah Paikek memiliki tiga bagian bentuk karya, pada bagian pertama mengabstraksikan kelembutan dan keanggunan serta kecantikan perempuan ketika sebelum menjadi seorang istri dan sedang menjadi seorang istri dalam simbol jari manis dan jari tengah. Suasana bahagia, tenang dan tegang. Bagian dua, mengabstraksikan bagaimana perempuan dalam peranan Limpapeh Rumah Nan Gadang melalui pelahiran simbol jari jempol dalam prosesi Malam Bainai, suasana tenang dan pada bagian ketiga mengabstraksikan bagaimana perempuan berperan sebagaimana kodrat perempuan Minangkabau yang dilahirkan melalui simbol jari telunjuk dan kelingking dalam prosesi Malam Bainai. Terdapat dua adegan makna jari telunjuk dan jari kelingking.

\section{4). Evaluasi}

Tahap evaluasi dimanfaatkan sebagai tahap pembakuan. Bentuk gerakan yang telah diolah melalui tahapan ekplorasi, improvisasi, dan komposisi/pembentukan dimatangkan dalam pola yang baku. Evaluasi dilakukan setiap selesai proses latihan mulai dari proses evaluasi gerak hingga pembentukan. Evaluasi dilakukan dalam kerampakan gerak penari, kualitas gerak, emosi dan ekspresi penari termasuk musik yang mendukung tari.

Evaluasi juga dilakukan dengan cara mengamati video latihan. Evaluasi karya tari Pituah Paikek juga dibantu dengan adanya proses bimbingan oleh pembimbing
Gorga : Jurnal Seni Rupa

Volume 10 Nomor 02 Juli-Desember 2021 p-ISSN: 2301-5942 | e-ISSN: 2580-2380

karya. Proses bimbingan dilakukan setelah pengkarya melakukan proses pembentukan bagian bagian struktur garapan karya. Pembimbing mengamati dan mengkoreksi terhadap hal hal yang perlu ditambah atau yang perlu dikurangi dalam mewujudkan karya Pituah Paikek.

\section{HASIL DAN PEMBAHASAN}

\section{Hasil}

\section{1). Struktur Karya}

Struktur lebih kepada hal-hal yang ditangkap oleh penonton melalui pikiran dibalik semua yang terlihat ketika dipertunjukan di atas panggung. Karya Pituah Paikek ditampilkan di gedung pertunjukan Hoeridjah Adam Institut Seni Indonesia Padangpanjang, Sumatera Barat. Karya tari Pituah Paikek ini berdurasi \pm 45 menit, dalam pertunjukan karya ini terdapat tiga bagian dengan lima adegan yang terjalin dalam rangkaian peristiwa. Di bagian pertama berdurasi 21 menit terdapat dua adegan. Bagian kedua berdurasi 6 menit terdapat satu adegan. Bagian ke tiga berdurasi 13 menit, terdapat dua adegan. Konsep ruang yang digunakan dalam pertunjukan tari Pituah Paikek adalah indoor (dalam ruangan).

Struktur penggarapan karya tari Pituah Paikek terdapat tiga bagian. Di bagian pertama terdapat tiga adegan. Bagian pertama adegan pertama berdurasi 5 menit, menggambarkan aktivitas malam bainai. Kegiatan ini biasa dilakukan oleh perempuan-perempuan Minangkabau yang ikut melancarkan prosesi malam bainai dan nasihat serta makna dari jari-jari yang diberi inai yang disampaikan melalui dendang. Berikut gambaran dari dendang yang berisikan nasihat kepada calon pengantin wanita:

"Bundo Kanduang "
Limpapeh Rumah Nan Gadang
Amban Puruak Pagangan Kunci
Kaunduang-unduang Kamadinah
Kapayuang Panji Kasarugo
Pusek Jalo Kumpalan Tali
Sumarak Dalam Nagari
Hiasan yo di Dalam Kampuang
Nan Tau di malu Jo sopan

"Bundo Kanduang “

Kaunduang-unduang Kamadinah

Pampalan Tali

Sumarak Dalam Nagari

Nan Tau di malu Jo sopan 

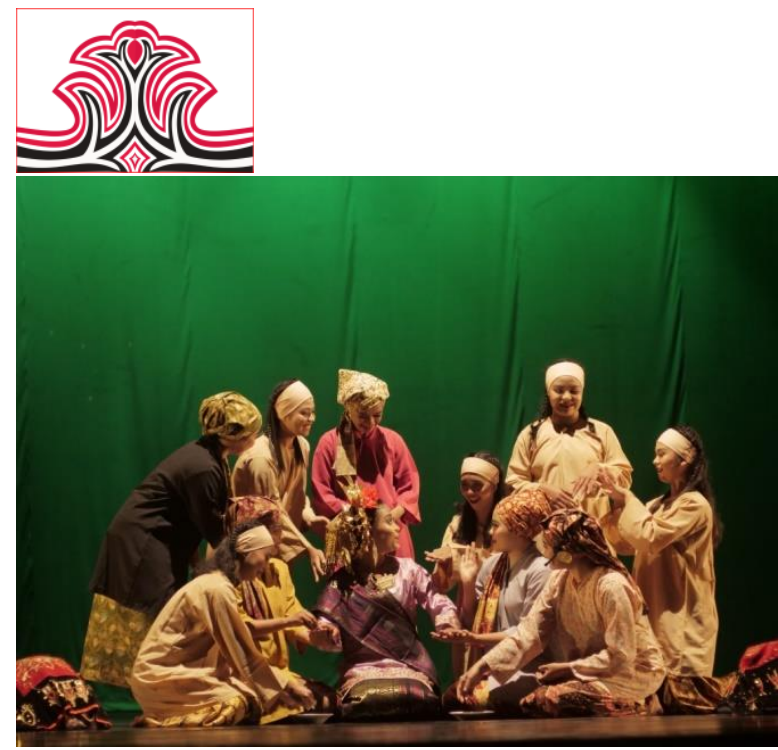

Gambar 1. Aktivitas Perempuan Minangkabau Saat Melekat Inai pada Jari-Jari Anak Daro (Lawranta, 2021)

Adegan kedua menggambarkan makna jari manis, yaiut kelembutan perempuan di Minangkabau, yang menyimbolkan seorang wanita dengan ke anggunan, kelembutannya dan kesucian. Pada bagian ini dua orang penari menggunakan properti selendang putih, satu orang tokoh dalam tari pituah paikek, di atas setting yang di bentuk seperti tempat penyelenggaraan Malam Bainai. Setelah itu masuk tiga penari kelompok dari kiri panggung. Adegan dua ini berdurasi 7 menit.

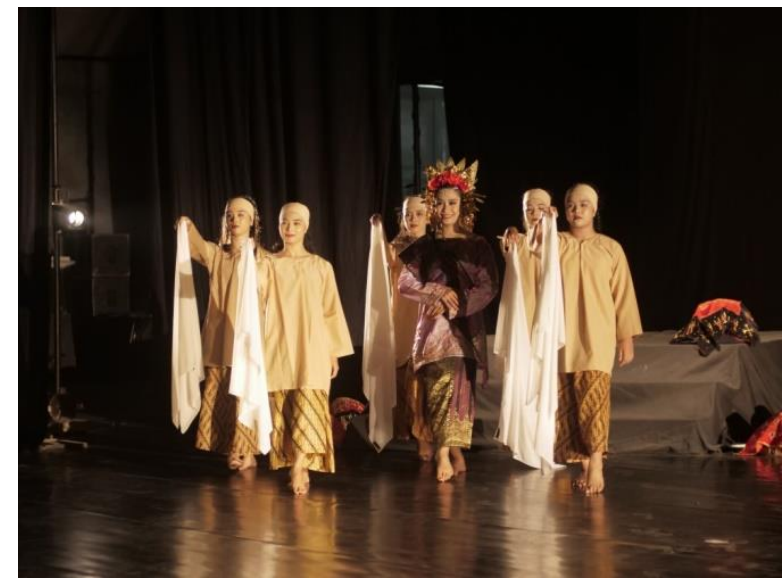

Gambar 2. Penggunaan Property Kain Putih. (Lawranta, 2021)

Adegan ketiga menggambarkan makna jari tengah berdurasi yang 6 menit, adegan ini melambangkan seorang perempuan yang menjadi tempat bersandar dan tempat menyelesaikan konflik yang akan terjadi di dalam rumah tangga. Munculnya dua orang penari yang menggambarkan kebingungan seorang perempuan ketika akan menjalani kehidupan rumah tangga. Lalu munculah salah satu penari perempuan dari kiri panggung yang menyimbolkan bahwasannya ketika seorang perempuan menjalani sebagai seorang istri dalam kehidupan rumah tangga maka mereka harus bisa menjadi tiang dalam rumah tangga seperti pepatah mengatakan " Kuat rumah karna sendih, rusak sendi rumah berbelah, kuat rumah karena istri, rusak istri rumah terbelah".
Gorga : Jurnal Seni Rupa

Volume 10 Nomor 02 Juli-Desember 2021 p-ISSN: 2301-5942 | e-ISSN: 2580-2380

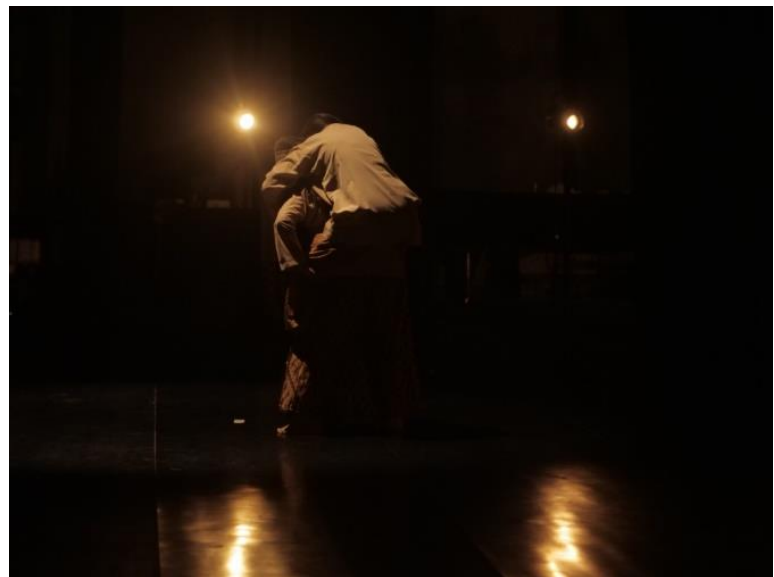

Gambar 3. Makna Jari Tengah Seorang Perempuan sebagai Penyelesai Konflik Rumah Tangga (Lawranta, 2021)

Bagian kedua berdurasi 10 menit terdapat dua adegan, adegan pertama yaitu makna dari jari jempol Bundo Kanduang perekat rumah gadang. Adegan ini diperkuat dengan kehadiran petatah-petitih Minangkabau:

"Limpapeh Rumah Nan Gadang, Samuik Tapijak Indak Mati, Alu Tataruang Patah Tigo ". "Bundo Kanduang limpapeh rumah nan gadang amban puruak pagangan kunci ka unduang-unduang kamadinah kapayuang panji kasarugo pusek jalo kumpulan tali sumarak dalam nagari hiasan io di dalam kampuang nan tau dimalu jo sopan ka mahias kampuang jo halaman sarato koto jo nagari sampai ka balai jo musajik sarato jo rumah tanggo lamahnyo nan tasabuik bana samuik tapijak indak mati kareh indak pailang aka alu tataruang patah tigo."

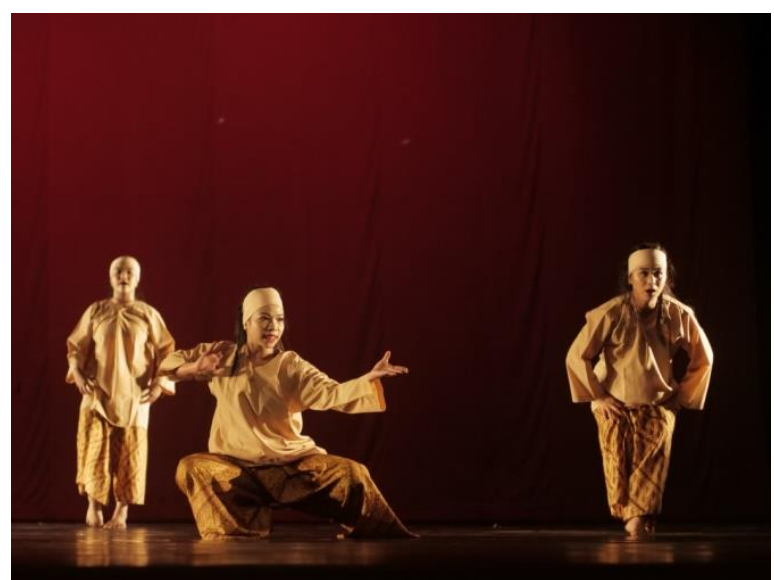

Gambar 3. Makna jari jempol makna Bundo Kanduang Limpapeh Rumah nan Gadang.

(Lawranta, 2021)

Bagian dua adegan dua 5 penari dan satu tokoh berdialog. Penari satu (perempuan), penari dua (namaku gadis), penari tiga (namaku perempuan), penari empat (namaku wanita), penari lima (namaku istri), satu orang penari tokoh (namaku ibu) 
Bagian ke tiga, terdapat dua adegan makna jari telunjuk dan jari kelingking. Jari telunjuk, sebagai penunjuk atas suatu budi pekerti dalam budaya Minang yang mentradisikan kepada keluarganya "tau di nan ampek" pada adegan ini penari perempuan berjumlah lima orang penari dengan adegan, salah satu penari naik ke atas punggung empat orang penari lainnya yang menyimbolkan bahwa perempuan harus tau sopan santun. Adegan ini diiringi oleh dendang yang berisikan:

"tau lah di kato, o lah kato, kato mendaki"

" tau lah di kato, o lah kato, o nan mandata "

" tau lah di kato, o lah kato, o nan malereang"

" tau lah di kato, o lah kato o nan manurun"

" tau di raso jo nan pareso, tau dimalu jo nan sopan”

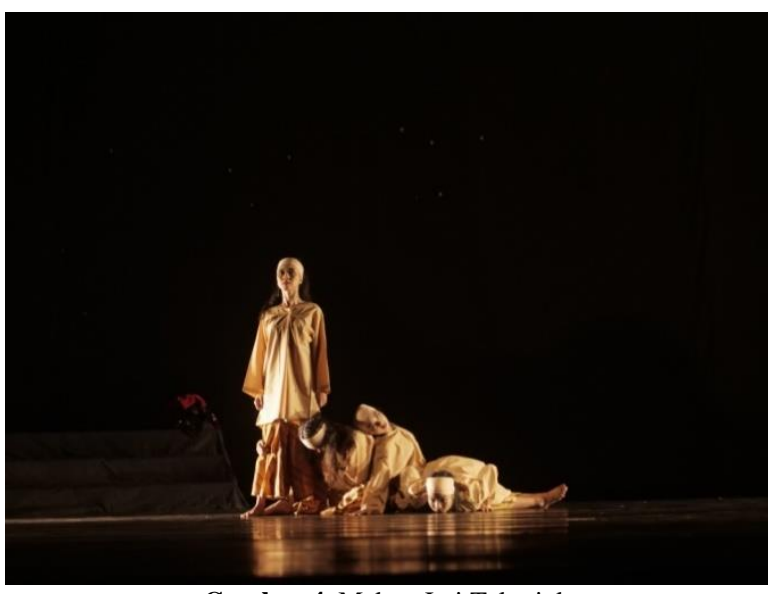

Gambar 4. Makna Jari Telunjuk

(Lawranta, 2021)

Adegan ke dua adalah makna jari kelingking mengambarkan betapa wanita memiliki kodrat dan kemampuan yang lemah di bandikan laki-laki dalam rumah tangga, calon pengantin wanita hendaknya bersama suami membina rumah tangga sebagai mana pepatah mengatakan "berat sama di pikul ringan sama di jinjing". Adegan ini dilakukan oleh lima orang penari dengan menggunakan selendang. Selendang tersebut di eksplorasi oleh penari dengan kedua tangan lalu selendang diputar, diikat kebadan dan dihempas ke lantai yang menggambarkan seorang perempuan melawan kodratnya ingin disetarakan dengan laki-laki. Lalu munculah satu orang penari perempuan dari kiri panggung dan naik keatas set panggung yang telah di siapkan, lalu penari tersebut memakai selendang ke atas kepala menutu rambut/ aurat agar kembali ke kodratnya sambil berdendang dengan makna di dalam rumah tangga seorang laki-laki adalah seorang pemimpin yang merangkul dan mengangkat derajat seorang perempuan dalam rumah tangga.
Gorga : Jurnal Seni Rupa

Volume 10 Nomor 02 Juli-Desember 2021 p-ISSN: 2301-5942 | e-ISSN: 2580-2380

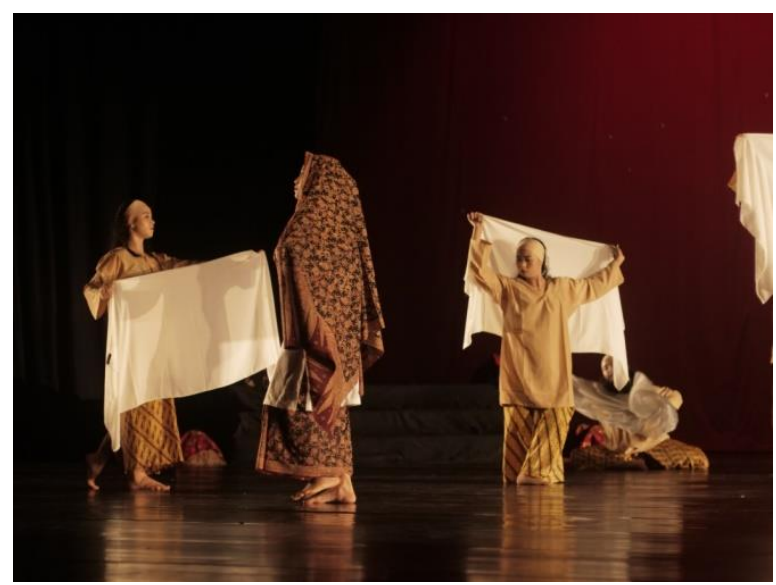

Gambar 5. Makna Jari Kelingking.

(Lawranta, 2021)

\section{Pembahasan}

1). Tekstur Karya

Tekstur merupakan sebuah wujud atau bentuk hasil pertunjukan dengan adanya setting, properti, tata cahaya, tata rias, kostum, gerak dan irama sebagai pelahiran suasana yang akan sampai kepada penonton. Hal-hal yang terserap melalui bentuk yang terlihat ketika dipentaskan.

\section{(1). Judul Tari}

Judul Pituah Paikek dipilih untuk menyampaikan tentang nasihat baik dari orang tua dan orang -orang yang dituakan tentang nasihat seputar rumah tangga dan saat melepas masa lajang, serta nilai-nilai nasehat dan tanggung jawab ketika akan menjadi seorang istri. Pituah paikek dianggap sebagai judul yang dapat menghantar orang lain untuk menangkap kesan dari persoalan yang ditawarkan. Kesan bahwa perempuan Minangkabau sebelum melepas masa lajang diberi nasihat dari orang yang dituakan atau yang sudah berpengalaman dalam menjalani kehidupan rumah tangga.

\section{(2). Tema Tari}

Tema tari dapat dipahami sebagai pokok permasalahan yang mengandung isi atau makna tertentu dari sebuah koreografi, baik bersifat literial maupun non-literial. Tema adalah sesuatu yang menjiwai cerita atau sesuatu yang menjadi pokok masalah dalam cerita. Dalam tema tersirat amanat atau tujuan pengarng menulis cerita.

Tema yang digunakan dalam penggarapan karya tari ini yaitu tema sosial. Dalam karya tari Pituah Paikek pengkarya terinspirasi dari sebuah fenomena tradisi Malam Bainai. Tema sosial terlihat dari fenomena itu sendiri di mana segala sesuatu atau tata nilai yang berlaku dalam sebuah masyarakat yang menjadi ciri khas masyarakat tersebut. 
Hal ini terlihat dalam prosesi Malam Bainai, dimana Malam Bainai menjadi salah satu perhelatan masyarakat Minangkabau ketika perempuan akan melepas masa lajang dan memiliki rangkaian acara pada prosesnya. Pada prosesi ini sanak saudara, kerabat, tetangga, teman dan masyarakat juga hadir untuk bersilaturahmi. Proses sosial ini telah menjadi budaya masyarakat untuk memberitahu kepada anak perempuan sebelum melepas masa lajang mereka akan diberi nasehat dan bekal dalm menjalani kehidupan berumah tangga.

\section{(3). Tipe Tari}

Karya tari Pituah Paikek ini menggunakan tipe yang sesuai adalah tipe dramatik yang mengandung arti bahwa gagasan yang di ungkapkan sangat kuat dan penuh daya pikat, dinamis, penuh ketegangan, dan dimungkinkan melibatkan konflik antara seorang dengan dirinya atau dengan orang lain. Tipe ini lebih memusatkan pada sebuah kejadian atau suasana tanpa menggunakan cerita. Pada karya ini penata memakai tipe dramatik karena penata menghadirkan peristiwa untuk menyampaikan maksud dari yang ingin disampaikan.

\section{(4). Gerak}

Konsep gerak karya tari Pituah Paikek merupakan dasar ekspresi pengkarya dalam mengilhami makna inai yang dilekatkan pada kuku calon pengantin wanita yang akan menjalani kehidupan rumah tangga melalui makna tersebut diolah menjadi konsep eksplorasi motivasi menjadi bentuk gerak. Dasar penciptaan gerakan adalah merasakan diri sebagai objek dari perempuan yang akan melepas maja lajang dan meinginterpretasikan makna kuku yan diberi inai sehingga pergerakan dominan hadir dalam karya Pituah Paikek adalah pergerakan yang menyampaikan maksud dan tujuan untuk memperlihatkan seperti apa perempuan Minangkabau ketika telah menjalani kehidupan rumah tangga. Adapun inspirasi dasar gerak yang akan digunakan dalam karya Pituah Paikek ini adalah gerak yang digunakan disesuaikan dengan konsep yang ingin disampaikan, seperti banyak menunakan teknik dasar tari minangkabau: pitunggua, balabeh dan lain-lain. Tari tradisi pun menjadi sumber gerak dalam karya tari ini, yaitu tari tradisi luambek.

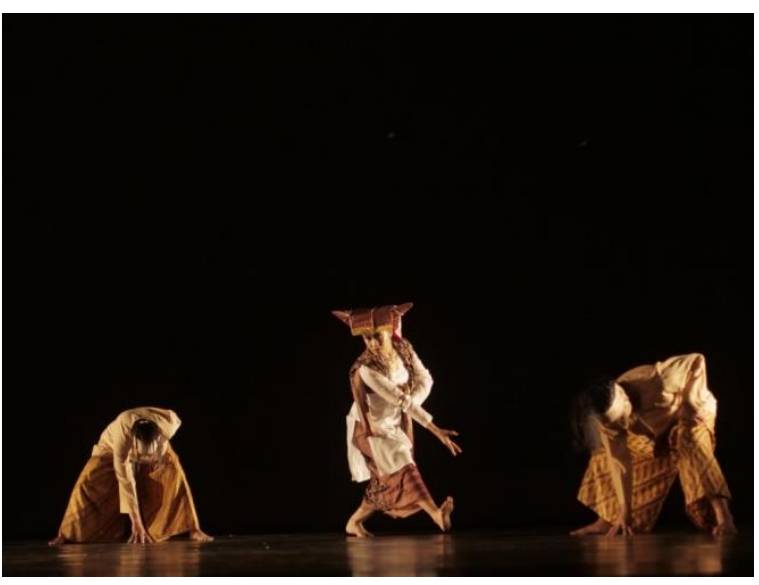

Gambar 6. Gerak Dasar Tari Ulu Ambek.

(Lawranta, 2021)

\section{(5). Penari}

Penari adalah seseorang yang dapat menguasai dan memadukan tiga unsur pokok antara lain: wirama, wirasa, dan wiraga. Bahwa seseorang penariakan berhasil apabila bisa menghubungkan atau menggabungkan tiga unsur tersebut. Penari merupakan pendukung utama dalam sebuah karya tari. Dalam karya tari Pituah Paikek koreografer memilih penari yang sesuai karakter yang di butuhkan dalam karya tari ini, karena peran penari akan menyampaikan pesan yang ingin di sampaikan pada karya tari Pituah Paikek, terdapat 6 orang penari perempuan, yang menggambarkan isian dalam karya tari Pituah Paikek.

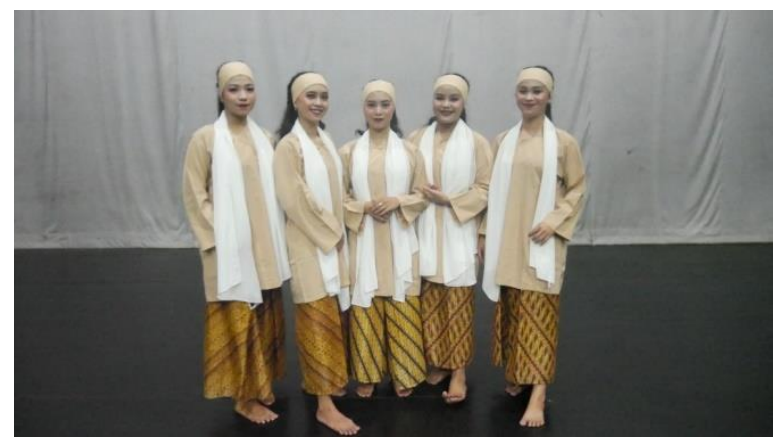

Gambar 7. Penari.

(Lawranta, 2021)

\section{(6). Tata Rias Busana}

Kostum dan rias merupakan salah satu unsur artistik yang sangat mendukung pertunjukkan sebuah tari, sehingga dapat menghidupkan dan menambah keindahan dari bentuk yang ditampilkan. Kostum yang akan di gunakan dalam garapan karya tari ini adalah kostum dengan motif dan desain yang berbeda dan memakai baju kurung basiba. 

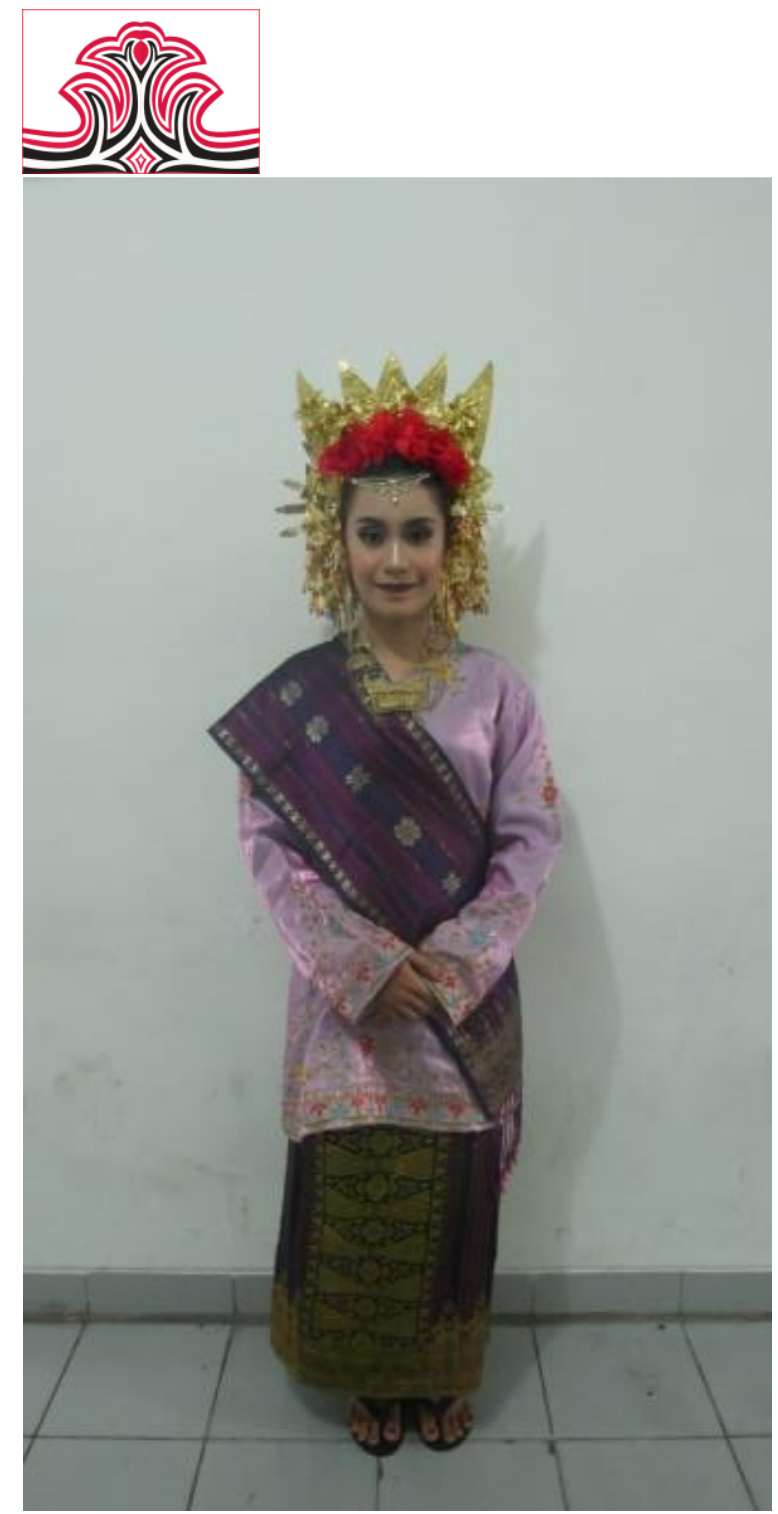

Gambar 8. Busana/Kostum Tokoh (Lawranta, 2021)

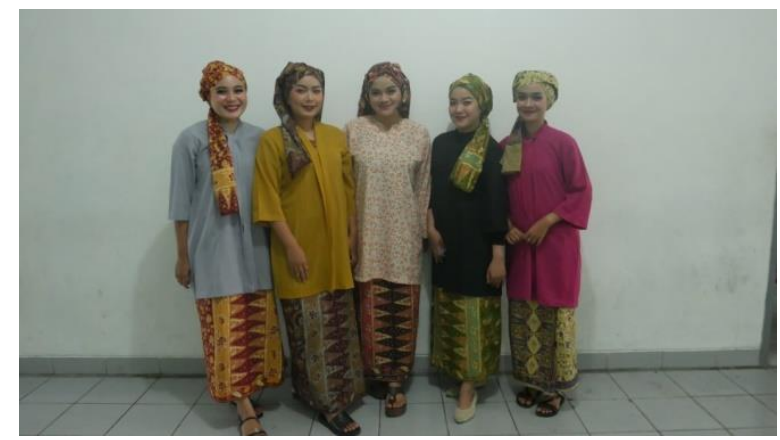

Gambar 9. Busana/Kostum Masyarakat (Lawranta, 2021)
Gorga : Jurnal Seni Rupa

Volume 10 Nomor 02 Juli-Desember 2021 p-ISSN: 2301-5942 | e-ISSN: 2580-2380

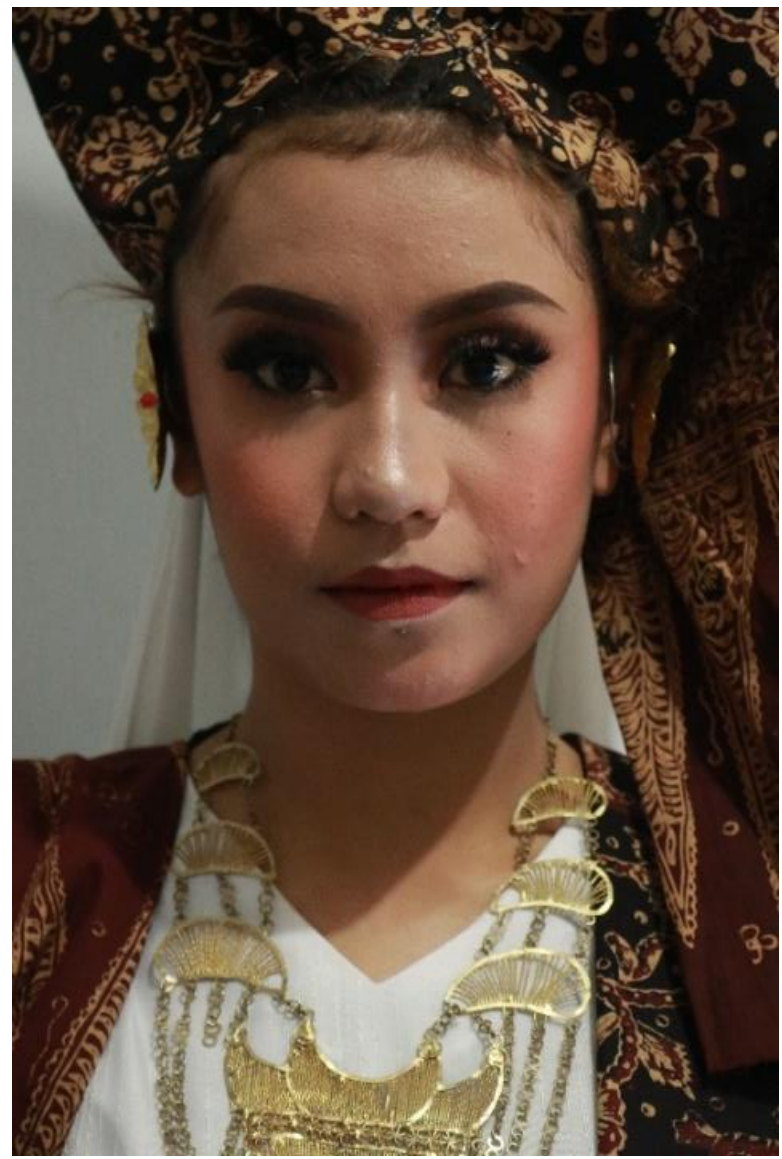

Gambar 10. Rias Cantik Panggung

(Lawranta, 2021)

\section{(7). Musik}

Karya ini menggunakan musik kombinasi ritmik dari nada-nada yang dapat melahirkan harmoni sebagai ungkapan ekspresi emosional dari musik tersebut, dan diolah kembali dengan variasi suasana yang diinginkan dalam garapan. Musik dalam karya tari Pituah Paikek berfungsi untuk memperkuat suasana yang dilahirkan dalam karya ini.

Pengkarya menggunakan musik tradisional Minangkabau yang dikembangkan sesuai alur garapnya. Konsep musik dalam karya tari Pituah Paikek adalah musik yang dimainkan secara langsung atau live. Adapun instrumen musik yang digunakan dalam karya ini yaitu alat musik tiup, alat musik pukul, dan vokal, seperti saluang, talempong, sarunai, gendang dol, canang, gong dan dendang. 


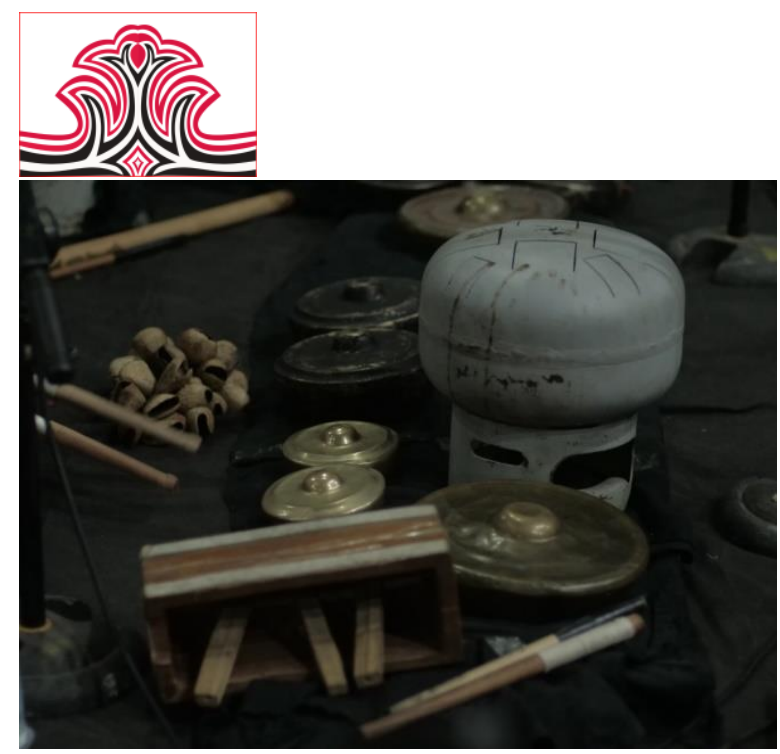

Gambar 11. Alat Musik Pengiring Karya Pituah Paikek

(Lawranta, 2021)

\section{(8). Properti dan Set Panggung}

Set panggung yang digunakan adalah kerangka Rumah Gadang dan nantinya setting ini dapat berubah bentuk sesuai dengan adegan yang akan dihadirkan. Properti yang akan digunakan pada baigian pertama yaitu selendang yang menyimbolkan kelembutan keanggunan perempuan Minangkabau. Properti selanjutnya adalah properti alu dan lasuang sebagai simbol aktifitas masyarakat.

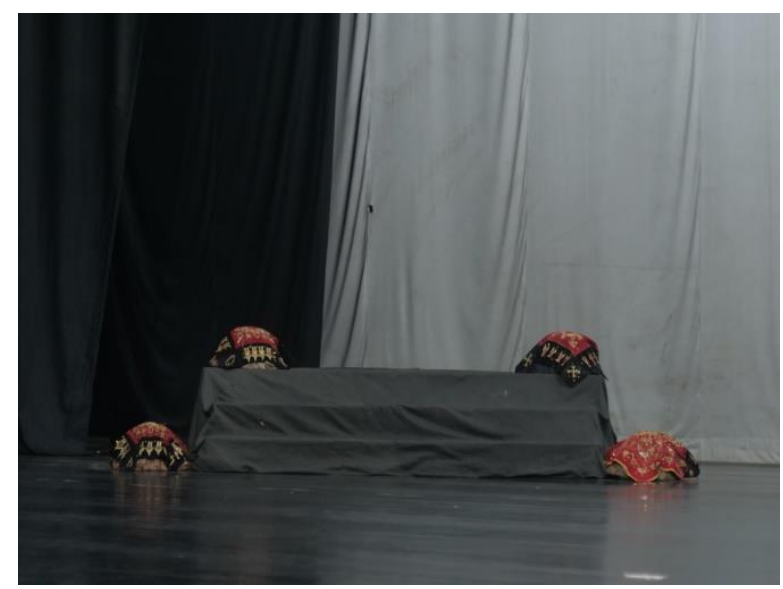

Gambar 12. Gambaran Properti dan Set Panggung (Lawranta, 2021)

\section{(9). Tempat Pertunjukkan}

Tempat pertunjukkan pada karya Pituah Paikek ini memakai konsep pertunjukkan indoor. Untuk mewujudkan konsep panggung ini, pola lantai penari disusun berdasarkan konvensi panggung proscenium. Hal inilah yang menjadikan alasan karya Pituah Paikek dipentaskan di gedung pertunjukan Hoeridjah Adam Institut Seni Indonesia Padangpanjang.
Gorga : Jurnal Seni Rupa

Volume 10 Nomor 02 Juli-Desember 2021 p-ISSN: 2301-5942 | e-ISSN: 2580-2380

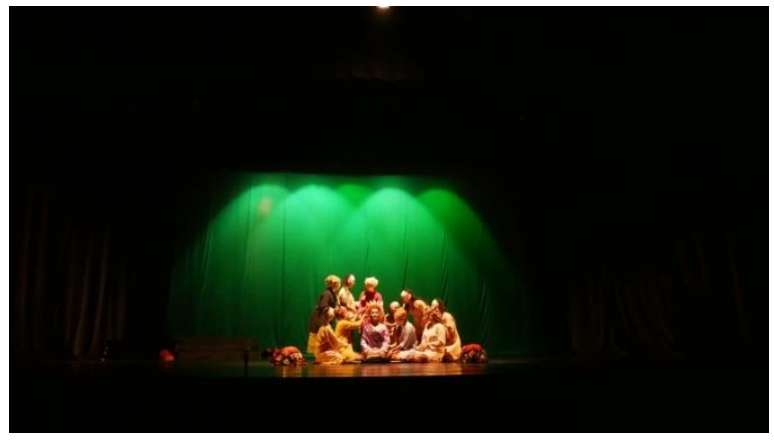

Gambar 13. Pentas Proscenium Gedung Pertunjukan Hoerijah Adam.

(Lawranta, 2021)

\section{KESIMPULAN DAN SARAN \\ 1.Kesimpulan}

Karya Pituah Paikek merupakan sebuah proses penciptaan tari yang dilandasi oleh riset terhadat fenomena budaya yaitu prosesi Malam Bainai. Malam Bainai di Minangkabau merupakan ritual melekatkan tumbukan daun pacar merah (inai) pada kuku- kuku jari calon pengantin wanita yang dilakukan pada malam sebelum hari perkawinan dan malam terakhir calon pengantin perempuan sebagai pelepas masa lajang.

Berdasarkan riset atas prosesi Malam Bainai, pengkarya melahirkan karya yang diberi judul Pituah Paikek yang mana pengkarya melihat dari sudut pandang berbeda bahwasannya Malam Bainai tidak hanya sekedar perhelatan melepas masa lajang namun ada nilai dan pesan ketika pemasangan inai pada setiap kuku jari calon pengantin wanita. Adanya nasehatnasehat yang ingin disampaikan ketika akan menjadi seorang istri dalam kehidupan berumah tangga.

Bentuk karya yang menjadi konsep dasar penciptaan adalah bentuk garapan tari kontemporer. Karya tari Pituah Paikek ini menggunakan tema sosial serta tipe dramatik. Fokus permasalahan dalam karya tari ini yaitu nilai-nilai dan makna yang terdapat pada inai yang dilekatkan di kuku jari calon pengantin wanita yang didalamnya terdapat makna pada setiap kuku jari tersebut. Karya tari ini memilih gerak dasar dari randai ulu ambek yang dikembangkan sesuai dengan konsep dan suasana yang akan digarap. Selain itu untuk memperkuat garapan ini pengkarya juga mengembangkan unsur-unsur musik Tradisional seperti saluang, bansi, dendang dan dikolaborasikan dengan alat musik tradisi lainnya yang nantinya akan mendukung karya Pituah Paikek.

\section{Saran}

Karya Pituah Paikek diproduksi di tengah pandemi Covid-19, sehingga banyak keterbatasan yang menghambat proses penciptaan karyanya. Kelemahan 


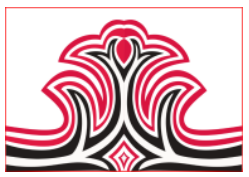

tersebut tentunya membuat penciptaan karya Pituah Paikek memiliki banyak kekukarangan dari segi pematangan konsep hingga penggarapan karya. Pengkarya menyadari bahwa karya tari Pituah Paikek belum maksimal. Maka dari itu, pengkarya membutuhkan kritik dan saran untuk mendukung dan melengkapi karya tari Pituah Paikek.

Semoga karya ini secara konsep dan pertunjukkan dapat memberikan informasi dan pengetahuan baru tentang makna dan nilai yang terkandung pada prosesi Malam Bainai. Pengkarya berharap laporan karya Pituah Paikek ini dapat dijadikan sebagai acuan untuk karya seni selanjutnya yang berangkat dari fenomena budaya Malam Bainai.

\section{DAFTAR RUJUKAN}

Alma M. Hawkins. (2003). Bergerak Menurut Kata Hati: Metoda Baru dalam menciptakan Tari (Terj. Iwayan Dibia). Indonesia: Masyarakat Seni Pertunjukan Indonesia (MSPI).

Devi, Cintya. (2019). "Malam Bainai". Hasil Wawancara Pribadi: 23 Agustus 2019, Padang.

Hadi, Sutrisno. (2007). Statistik 2. Yogyakarta: Andi Offset.

Kurniawan. (2001). Semiologi Roland Barthes. Magelang: Yayasan Indonesia Tera.

Lawranta, Gangga. (2021). "Malam Bainai". Hasil Dokumentasi Pribadi: 31 Juli 2021, Padangpanjang.

Mak Katik. (2021). "Malam Bainai". Hasil Wawancara Pribadi: 18 Februari 2021, Padang.

Oktora, D. R., Amsia, T., \& Syaiful, M. (2017). Tradisi Malam Bainai pada Acara Perkawinan Adat Padang Pariaman di Kecamatan Rajabasa Kota Bandar Lampung. PESAGI (Jurnal Pendidikan dan Penelitian Sejarah), 5(7).

Supriyanto, Eko. (2018). Ikat Kait Impulsif Sarira: Gagasan yang Mewujud Era 1990-2010. Yogyakarta: Penerbit Garudhawaca.

Sylvia, S., Syahrel, S., \& Marzam, M. (2014). Struktur Penyajian Malam Bainai pada Pesta Perkawinan di Kota Padang. Jurnal Sendratasik, 3(3), 71-78.

Yudiaryani, dkk. (2017). Karya Cipta Seni Pertunjukan. Yogyakarta: JB Puplisher Bekerjasama Dengan Fakultas Seni Pertunjukan, Institut Seni Indonesia Yogyakarta.

Zaimiati. (2019). "Malam Bainai". Hasil Wawancara Pribadi: 23 Agustus 2019, Padang. 